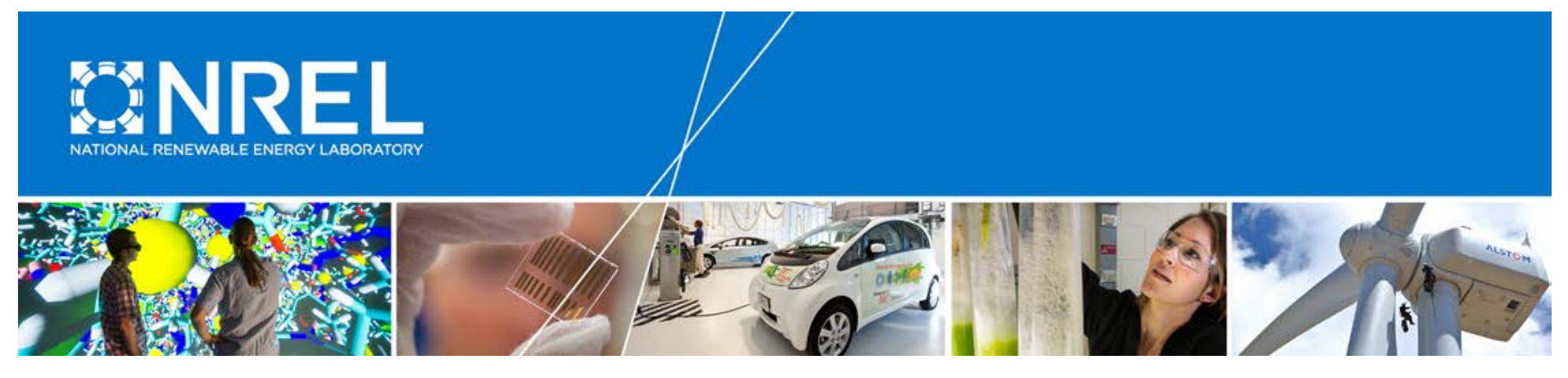

\title{
Manufacturing a 9-Meter Thermoplastic Composite Wind Turbine Blade
}

\section{Preprint}

Robynne E. Murray, David Snowberg, Derek Berry, Ryan Beach, and Sam Rooney National Renewable Energy Laboratory

Dana Swan

Arkema Inc.

Presented at the American Society for Composites 32nd Technical Conference West Lafayette, Indiana October 23-25, 2017

NREL is a national laboratory of the U.S. Department of Energy Office of Energy Efficiency \& Renewable Energy Operated by the Alliance for Sustainable Energy, LLC

This report is available at no cost from the National Renewable Energy Laboratory (NREL) at www.nrel.gov/publications.

Conference Paper

NREL/CP-5000-68615

December 2017 


\section{NOTICE}

The submitted manuscript has been offered by an employee of the Alliance for Sustainable Energy, LLC (Alliance), a contractor of the US Government under Contract No. DE-AC36-08GO28308. Accordingly, the US Government and Alliance retain a nonexclusive royalty-free license to publish or reproduce the published form of this contribution, or allow others to do so, for US Government purposes.

This report was prepared as an account of work sponsored by an agency of the United States government. Neither the United States government nor any agency thereof, nor any of their employees, makes any warranty, express or implied, or assumes any legal liability or responsibility for the accuracy, completeness, or usefulness of any information, apparatus, product, or process disclosed, or represents that its use would not infringe privately owned rights. Reference herein to any specific commercial product, process, or service by trade name, trademark, manufacturer, or otherwise does not necessarily constitute or imply its endorsement, recommendation, or favoring by the United States government or any agency thereof. The views and opinions of authors expressed herein do not necessarily state or reflect those of the United States government or any agency thereof.

This report is available at no cost from the National Renewable Energy Laboratory (NREL) at www.nrel.gov/publications.

Available electronically at SciTech Connect http:/www.osti.gov/scitech

Available for a processing fee to U.S. Department of Energy and its contractors, in paper, from:

U.S. Department of Energy

Office of Scientific and Technical Information

P.O. Box 62

Oak Ridge, TN 37831-0062

OSTI http://www.osti.gov

Phone: 865.576.8401

Fax: 865.576.5728

Email: reports@osti.gov

Available for sale to the public, in paper, from:

U.S. Department of Commerce

National Technical Information Service

5301 Shawnee Road

Alexandria, VA 22312

NTIS http://www.ntis.gov

Phone: 800.553 .6847 or 703.605 .6000

Fax: 703.605.6900

Email: orders@ntis.gov 
Paper Number: 1500

Title: Manufacturing a 9-Meter Thermoplastic Composite Wind Turbine Blade

Authors: Robynne E. Murray, Dana Swan, David Snowberg, Derek Berry, Ryan Beach, Sam Rooney 


\begin{abstract}
Currently, wind turbine blades are manufactured from a combination of glass and/or carbon fiber composite materials with a thermoset resin such as epoxy, which requires energy-intensive and expensive heating processes to cure. Newly developed in-situ polymerizing thermoplastic resin systems for composite wind turbine blades polymerize at room temperature, eliminating the heating process and significantly reducing the blade manufacturing cycle time and embodied energy, which in turn reduces costs. Thermoplastic materials can also be thermally welded, eliminating the need for adhesive bonds between blade components and increasing the overall strength and reliability of the blades. As well, thermoplastic materials enable end-oflife blade recycling by reheating and decomposing the materials, which is a limitation of existing blade technology.

This paper presents a manufacturing demonstration for a 9-m-long thermoplastic composite wind turbine blade. This blade was constructed in the Composites Manufacturing Education and Technology facility at the National Wind Technology Center at the National Renewable Energy Laboratory (NREL) using a vacuumassisted resin transfer molding process. Johns Manville fiberglass and an Arkema thermoplastic resin called Elium were used. Additional materials included Armacellrecycled polyethylene terephthalate foam from Creative Foam and low-cost carbonfiber pultruded spar caps (manufactured in collaboration with NREL, Oak Ridge National Laboratory, Huntsman, Strongwell, and Chomarat). This paper highlights the development of the thermoplastic resin formulations, including an additive designed to control the peak exothermic temperatures. Infusion and cure times of less than 3 hours are also demonstrated, highlighting the efficiency and energy savings associated with manufacturing thermoplastic composite blades.
\end{abstract}




\section{INTRODUCTION}

With a U.S. goal of $20 \%$ wind power integration by 2030 [1], wind turbine developers are moving toward larger blades to increase turbine power capture. However, as blade sizes increase, developers face challenges with the time and energy requirements for blade manufacturing and transportation. Wind turbine blades are typically manufactured from a combination of glass and/or carbon fiber composite materials with a thermoset resin such as epoxy, which requires a heating process to cure. With material and labor costs accounting for $51 \%$ and $41 \%$ of the total blade cost, respectively [2], emphasis on manufacturing methods that reduce cycle time and energy consumption can lead to overall cost reductions. Advances in blade manufacturing automation have reduced manufacturing times from 38 hours to 24 hours per blade [3]; however, these processes remain energy-intensive and expensive as a result of the heating process required to cure thermoset-matrix composites. Further, blades manufactured with thermoset resins require adhesives to bond the lowand high-pressure blade skins. Adhesive bonding is a time-consuming process, and results in stress concentrations and areas of weakness that decrease the reliability and life span of wind turbine blades [4].

Recently developed in-situ reactive thermoplastic resin systems polymerize (referred to here as curing) at room temperature, thus eliminating the need for heated blade molds for initial cure and additional ovens for postcure, thereby reducing manufacturing costs [5]. Thermoplastic materials can be thermally welded, eliminating the need for adhesive bonds between blade skins and increasing the overall strength and reliability of the blades, and can be reformed by applying high temperatures, enabling easier repair and maintenance. This ability presents a potential advantage over currently used thermoset resins such as epoxy, which cannot be reformed other than by machining, and putting the material properties at risk of damage. With less heat required for cure and the ability to thermally weld blade components, on-site manufacturing becomes a viable option - ultimately removing the transportation limitations to accommodate bigger blades. Transportation of components to a site influences the cost and drives the energy payback period, as the specialized equipment and logistics/permitting required, as well as fuel for transportation, can be extensive - which further exemplifies the need to explore new, more affordable manufacturing capabilities.

With an emphasis on the entire life cycle energy usage, recycling of wind turbine blades also needs to be increased. Currently only a small percentage of turbine blades are recycled during the decommissioning stage because of the complexity of their composition and materials used [6] and the cross-linked nature of thermoset materials [7]. Thermoplastic materials can be recycled at the end of their life span by reheating and decomposing the materials, aligning this technology development with the Institute for Advanced Composites Manufacturing Innovation's technical goal of $80 \%$ recyclability in 5 years [8].

\section{Objectives}

In-situ reactive thermoplastic resins have only recently reached a level of maturity that allows them to be used as a composite matrix material without the need for costly tooling due to the exothermic reaction during curing. For this technology to become 
commercially viable, manufacturing processes and efficient cycle times need to be demonstrated, material and structural properties of blades need to be verified, and cost modeling performed. This paper presents the first stage of this effort: manufacturing a 9-m-long thermoplastic composite wind turbine blade to demonstrate manufacturing capabilities. To date, this is the first time in the United States that a wind turbine blade has been manufactured using a thermoplastic resin matrix material and vacuumassisted resin transfer modeling (VARTM) process. This paper outlines the manufacturing developments and lessons learned during this process, which are critical steps toward verifying thermoplastic wind turbine technology.

\section{METHODOLOGY}

Most wind turbines have megawatt-size blades (ranging between 30 and $70 \mathrm{~m}$ ); however, for pragmatic reasons, the thermoplastic manufacturing processes were initially developed at a smaller scale. For the work presented herein, a 9-m blade was manufactured using tooling from TPI Composites that was developed as part of Sandia National Laboratories' Blade System Design Study (BSDS) blade design and manufacturing project in 2008 [9]. Through the BSDS project, this blade geometry was designed to demonstrate the advantages of integrating aerodynamic and structural design and manufacturing efforts. The blade design and tooling that was developed through the BSDS project and used for this work was found to be more efficient and cost effective to build than prior 9-m blade designs developed through the BSDS project. Figure 1 is a CAD model of the 9-m blade that shows two spar caps, one on the high-pressure (HP) and low-pressure (LP) skins aligned along the aerodynamic center, and a C-beam shear web.

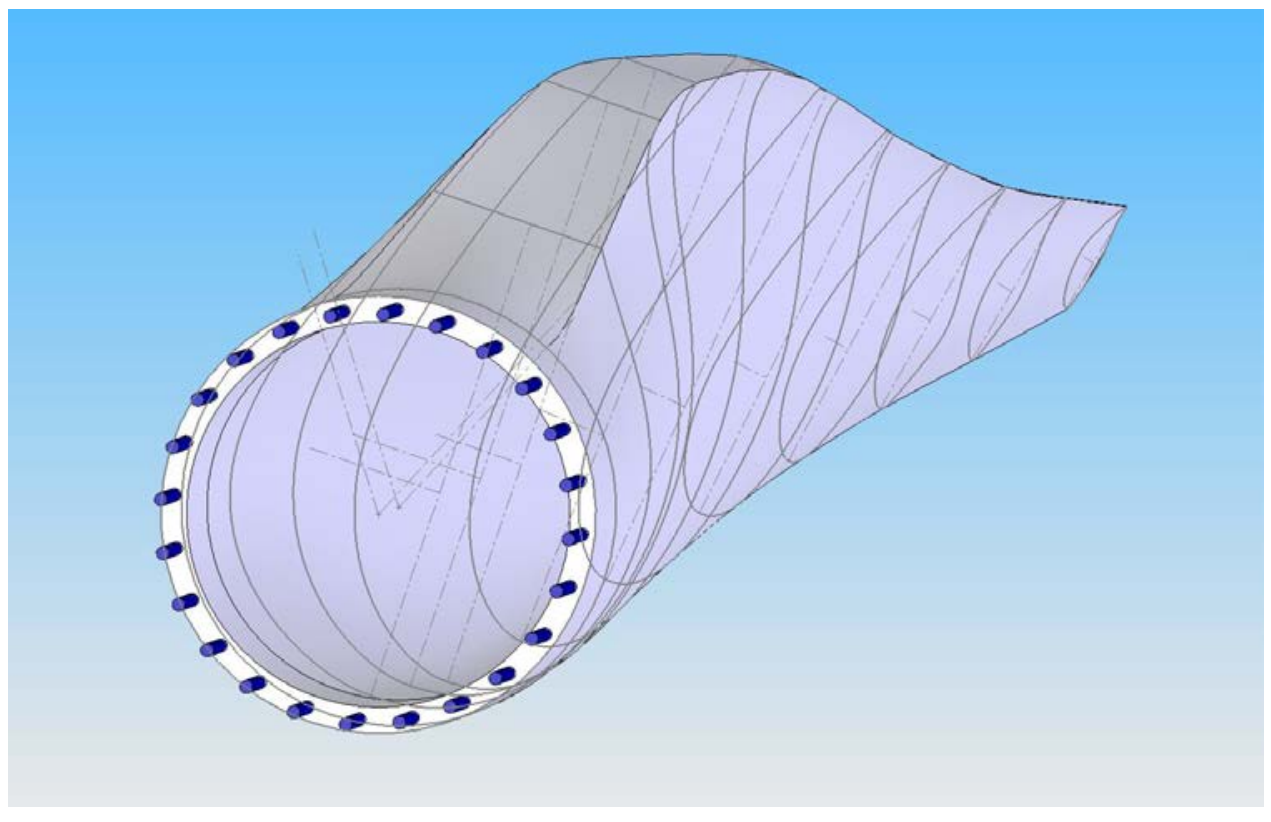

Figure 1. CAD model of the BSDS blade geometry (Courtesy TPI/Sandia National Laboratories).

Of the manufacturing methods employed to construct large wind turbine blades, VARTM and prepreg account for around $94 \%$ of blades manufactured worldwide [2]. With the low viscosity of the resin used, and the compatibility of the existing tooling, 
the VARTM method was used for this demonstration. The general procedure included preparing the mold with Chemtrend sealant and Chemlease 70 EZ release coat, and applying a gel coat layer that consisted of a combination Marine Clear gel coat and $1.5 \%$ methyl ethyl ketone peroxide (MEKP), which was applied with a paint brush. Next, a layer of veil fabric, the fiberglass layers, spar caps, and core materials were applied, followed by a final fiberglass layer to sandwich the core materials. Peel ply and flow media (primarily Compoflex and Greenflow flow media) were then applied, and the vacuum and resin feed lines were configured. The part was vacuum bagged with Airtech Stretchlon 800 bag and drop tested to ensure no air leaks. The part was then infused, and, once fully wet out, was left at room temperature to cure.

\section{MATERIALS}

A combination of Johns Manville Biax fiberglass $\left(650 \mathrm{~g} / \mathrm{m} 2 \pm 45^{\circ}\right)$ and Saertexstitched Triax fiberglass $\left(1,173 \mathrm{~g} / \mathrm{m} 2,567 \mathrm{UD} / 300+45^{\circ} / 300-45^{\circ} / 6\right.$ stitching $)$ were used in the blade skins and shear web. A combination of 3/8-inch-thick Armacell foam supplied by Creative Foam and 3/8-in.-thick balsa wood core were sandwiched between the fiberglass layers of the blade skins. Four-in.-wide pultruded spar caps were used, made from low-cost unidirectional carbon fiber in collaboration between Huntsman, Strongwell, NREL, Oak Ridge National Laboratory, and Chomarat.

\section{Resin characterization}

The resin used for this demonstration was an Arkema Inc. acrylic thermoplastic material called Elium. The Elium resin is a liquid at room temperature with viscosity ranging between 100 and $500 \mathrm{cPs}$. It is a two-part reactive system in which part A is the Elium resin and part B is Arkema's Luperox organic peroxide. For this work, the resin was processed using traditional thermoset methods but cured at room temperature without external heating, enabling parts to be demolded after the initial cure cycle with no postcure necessary.

The material properties of the Elium resin were verified through material testing of neat resin panels made by a cast process prior to blade manufacturing, with results given in TABLE 1. The International Standards Organization method used for each test is also given in this table.

TABLE 1. ELIUM RESIN MATERIAL PROPERTIES.

\begin{tabular}{llll}
\hline \multicolumn{1}{c}{ Property } & Value & Units & Test Method \\
\hline Tensile Strength & 76 & $\mathrm{MPa}$ & ISO 527 \\
Tensile Modulus & 3,300 & $\mathrm{MPa}$ & ISO 527 \\
Flex Strength & 130 & $\mathrm{MPa}$ & ISO 178 \\
Flex Modulus & 3,250 & $\mathrm{MPa}$ & ISO 178 \\
Compressive Strength & 130 & $\mathrm{MPa}$ & ISO 684 \\
Fracture Toughness, $\mathrm{K}_{1 \mathrm{c}}$ & 1.2 & $\mathrm{MPa}^{1 / 2}$ & ISO 13586 \\
\hline
\end{tabular}

The properties given in TABLE 1 are similar to typical epoxy resin systems used in wind blade production [10]. The Elium resin is available in different grades depending on the viscosity, processing method, open time, and reactivity needed for the application. The Elium 188 grade was chosen for the wind blade demonstration because of the long open time needed, as well as its low viscosity and moderate cure time. The percentage of Luperox peroxide used in the resin varied between $2 \%$ and 
$3 \%$, depending on the required open time, with a greater percentage of Luperox resulting in a decreased open time.

Although there are many advantages to using thermoplastic resins, one area of concern is the temperature increase caused by the exothermic reaction, which can damage the tooling and affect the quality of the final part. The reaction between the Elium resin and the Luperox peroxide is exothermic in nature and when thick parts (12 $\mathrm{mm}$ or greater) are infused, the exothermic temperature can exceed the boiling point $\left(100^{\circ} \mathrm{C}\right)$ of the resin, causing voids and imperfections in the laminate stack. An exothermic control additive (ECA) was developed to help control the peak exothermic temperature. However, prior to being used for the 9-m blade, it was critical to verify that the addition of the ECA did not negatively affect the mechanical properties of the panel. To verify this, $12.7-\mathrm{mm}$ flexural testing panels were manufactured via VARTM using 20 plies of a PPG 2026 unidirectional fiberglass material. One set of panels was infused with the Elium 188 system and the other set was made with the Elium 188 and 1,000 ppm of ECA. The samples were prepared and tested in three-point bending according to ASTM D790. Stress-strain curves are shown in Figure 2 and Figure 3. The failure stress, standard deviation, and Young's modulus are summarized in Table 2 (data shown in this table was obtained by Arkema Inc.).

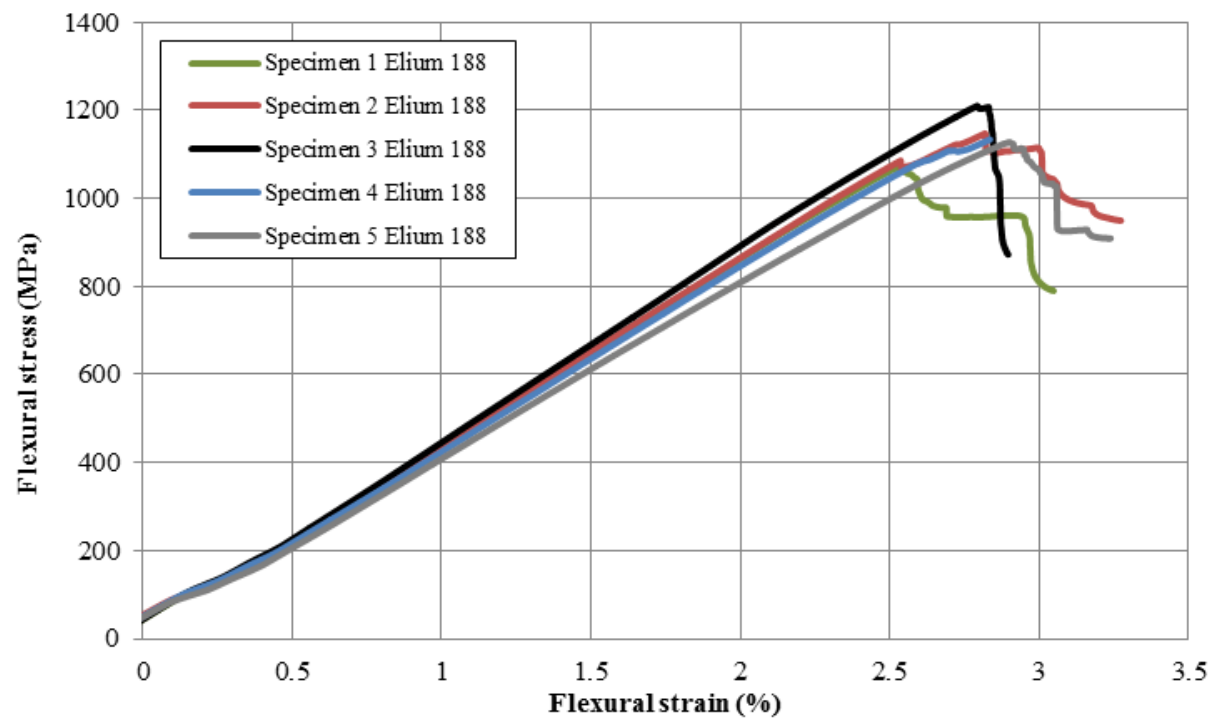

Figure 2. Stress-strain curves for five test specimens with Elium 188 without ECA (data obtained by Arkema Inc.). 


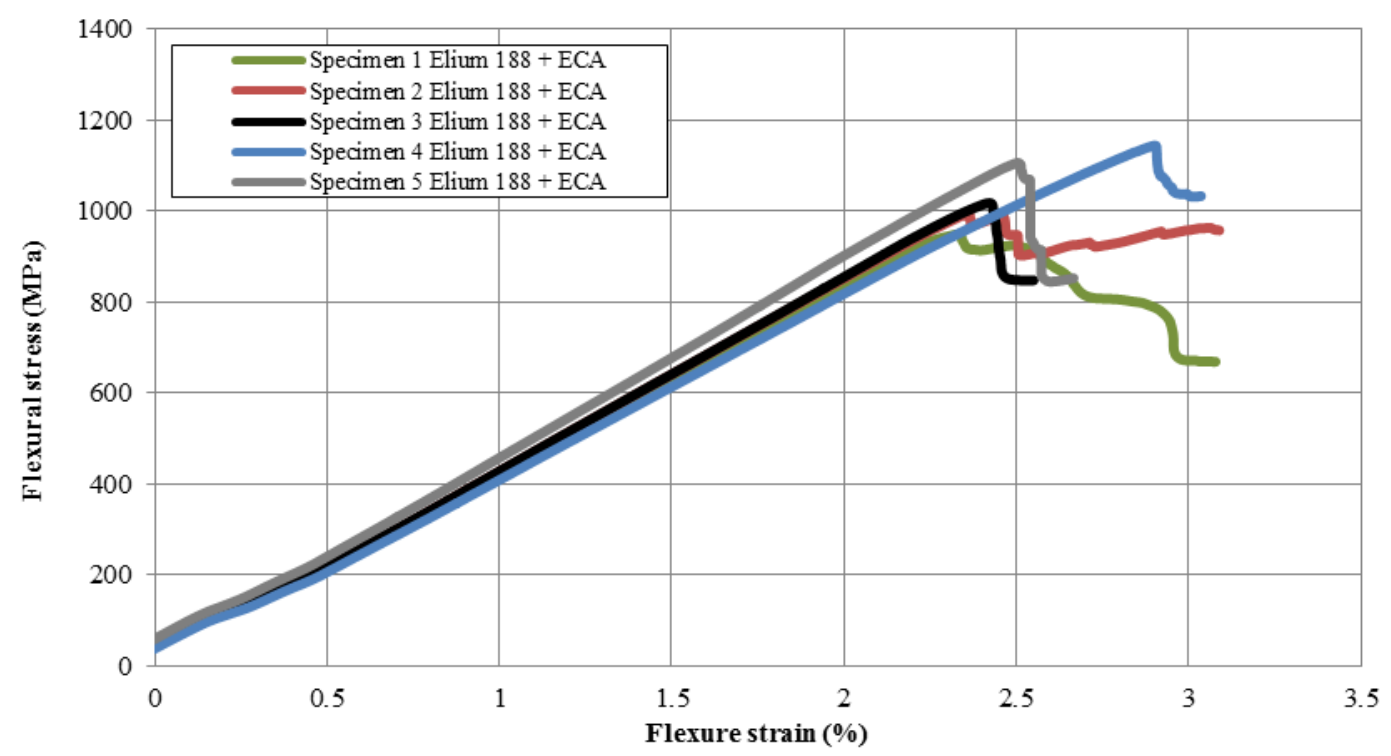

Figure 3. Stress-strain curves for five test specimens with Elium 188 with ECA (data obtained by Arkema Inc.).

TABLE 2. FLEXURAL TESTING RESULTS FOR ELIUM FORMULATIONS.

\begin{tabular}{l|cc}
\hline \multicolumn{1}{c|}{ Sample } & $\begin{array}{c}\text { Failure Stress } \\
(\mathrm{MPa})\end{array}$ & $\begin{array}{c}\text { Flexure Modulus } \\
(\mathrm{GPa})\end{array}$ \\
\hline Elium 188 & $1131 \pm 34$ & 43.0 \\
Elium 188 + ECA & $1042 \pm 72$ & 42.7 \\
\hline
\end{tabular}

Results of the flexural tests showed that the average failure stress of the laminates with the ECA was 7.8\% lower and the Young's modulus was less than 1\% lower than the average for the panels without the ECA. With a standard deviation of approximately $4 \%$, this suggests that the use of the ECA does not significantly degrade the material properties, and hence the advantages of the exothermic control outweigh this slight decrease in the failure stress.

\section{MANUFACTURING BLADE SUBSECTIONS}

Techniques for infusing the fiberglass blade with the Elium resin were developed through a series of trials prior to the final blade build. This process included manufacturing several laminate plates with varying thicknesses and several blade subsections, which are presented herein. These trials were used to optimize the resin system for the various laminate geometries encountered during a blade build, including variables such as the initiator charge and ECA loading. This section outlines the blade subsection manufacturing trials.

\section{Maximum chord section}

Two blade subsections approximately $100 \mathrm{~cm}$ long at the maximum chord location of the blade were manufactured to determine the appropriate resin mixture and infusion procedure for the more complex geometry that includes the spar cap and balsa core. For these trials, the resin was mixed with $2 \%$ Luperox peroxide and no $\mathrm{ECA}$, as the laminate was reasonably thin and the temperatures during the exothermic 
reaction were not expected to be an issue. Figure 4 shows one of the maximum chord sections, including the flow media configuration and the final product.
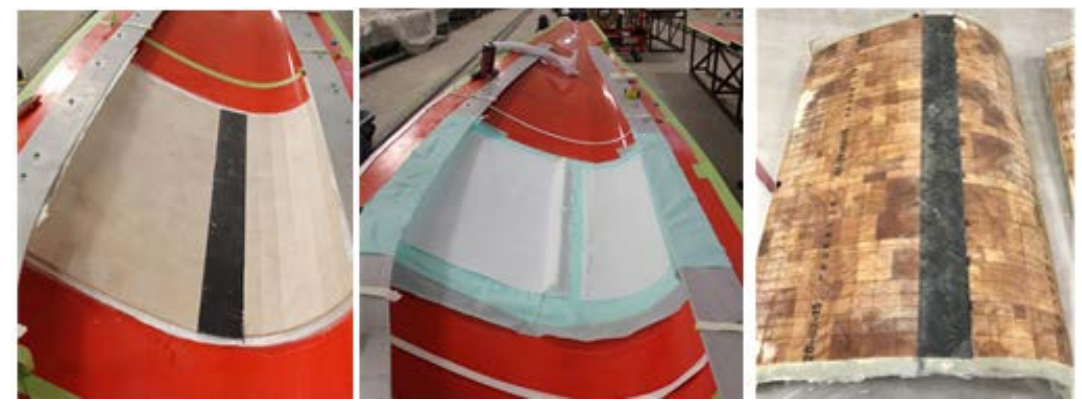

Figure 4. Photos of maximum chord blade section manufacturing: Balsa core and spar cap (left), second layer of fiberglass and Compoflex flow media (center), and the finished product (right).

The infusion process took approximately 60 minutes, and full cure was reached after approximately 85 minutes for the maximum chord subsections. During the first subsection trial, the Compoflex flow media was used over the entire section to within 1 in. of the part edges. During infusion, it was found that the resin quickly reached the trailing edge and then began race-tracking and entering the vacuum lines before it reached the leading edge, which never fully wet out. In the second trial, shown in Figure 4, a break in the Compoflex flow media was used next to the feed line on the trailing-edge side. This approach slowed the resin progression and resulted in a more complete wet out of the part; however, there was still a small dry spot on the leadingedge side of the panel. For the full blade construction, more feed lines were put in place on the trailing-edge side of the blade to assist in wetting out this area.

\section{Blade root}

The 504-mm-diameter root section of the blade consists of 34 layers of fiberglass composite material that are tapered down to two layers toward the outer span (total thickness of approximately $32 \mathrm{~mm}$ tapering to $8 \mathrm{~mm}$ ). This thickness can pose challenges in wetting out and therefore infusing the thick root was explored prior to the full blade build to determine an appropriate through-thickness infusion process and resin formulation. As a trial, a 100-cm-long section at the root of the blade was constructed, including the spar caps and tapered fiberglass layers. This section is shown in Figure 5. 

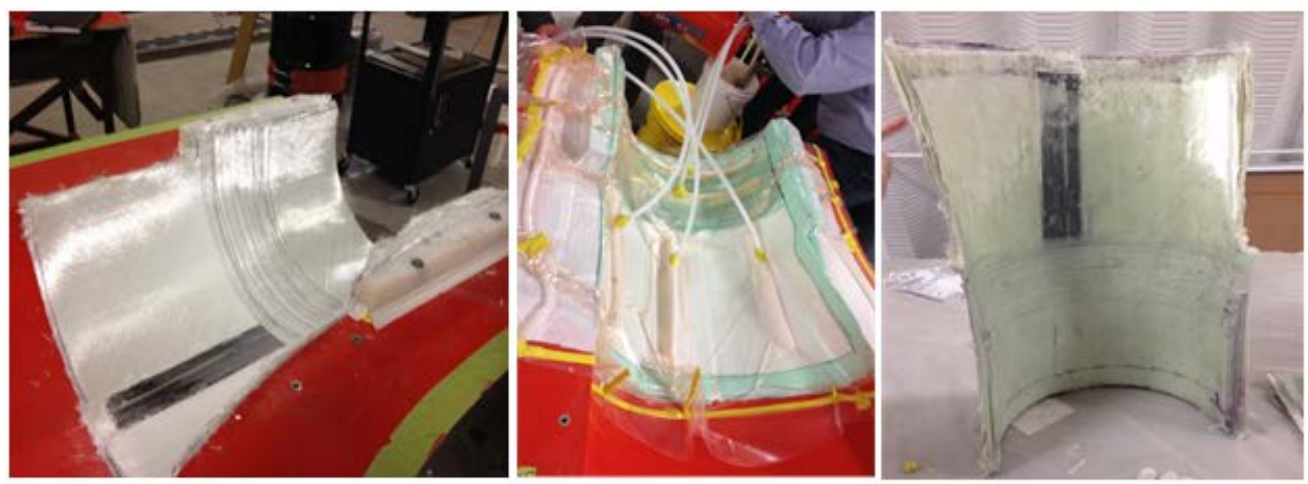

Figure 5. Root section trial photographs: composite layup (left), vacuum bag, feed lines, and infusion process (center), and the finished product (right).

To assist the resin transfer through the thickness of the blade, a 4-in.-wide (same width as the spar caps) layer of chop strand mat $\left(225 \mathrm{~g} / \mathrm{m}^{2}\right)$ was placed under the spar cap and extended past the root by 18 inches. The additional layers of fiberglass were added on top, then the chopped strand mat was flipped on top of the final layer to assist resin transfer from the feed lines on the B-side into the bottom layers of the thick root on the A-side. Two percent of Luperox was used to allow the resin sufficient open time to infuse into the thick section prior to kicking (initiation of the curing reaction), and approximately $800 \mathrm{ppm}$ of the ECA was used to decrease the peak exotherm in the thick layers, which would be more resin rich. The infusion was initiated at the root first, allowing the resin to infuse through a radial feed line for 20 minutes before a second central radial feed line in the thinner section along the spar cap was opened. After the main feed line was open for approximately 20 minutes, an additional axial feed line on the leading edge around the maximum chord was opened as well to aid chord-wise resin flow in this area. Several backup feed lines were positioned but not used, and acted as vents for off-gassing of the resin reaction. The total infusion process took approximately 80 minutes, followed by 45 minutes of cure time.

Once the skin was fully wet out, the resin started to kick at the thick section first, reaching a peak exotherm at approximately $98^{\circ} \mathrm{C}$ and curing within an hour of infusion. The part was demolded after being left in the mold for 10 hours (overnight). Although the part fully wetted out, the thinner outer span section had areas that were polymerized but not hard compared to the thicker section. This outcome suggests that the ECA was effective in maintaining the peak exotherm at the resin-rich root, but the peak exotherm was not high enough to generate high molecular weight chains at the thinner section, and instead a lower molecular weight polymer/oligomer resulted, leading to lower tensile properties. This result highlights the importance of using the appropriate amount of the ECA for the laminate thickness. Based on these findings, for the 9-m blade skins, two batches of resin were mixed. The ECA was used for the thick root section but no ECA was used for the thinner outer span of the blade. In addition, $2 \%$ Luperox was used at the root section to give sufficient open time for the resin to infuse, and 3\% was used for the rest of the blade as the thinner laminate required shorter open time and did not hinder resin infusion. 


\section{Drilling}

For typical blade manufacturing, holes are drilled and rods are inserted in the blade root to attach the blades to the turbine hub. This process makes drilling through the thick root section an important part of manufacturing. Research has shown that thermoplastics have some advantages in machining compared to more brittle thermoset materials, which are susceptible to delamination at the hole entrance [11]. However, the nature of thermoplastic materials is to reform with heat, therefore friction and heat during drilling are important considerations because the material may soften plastically and adhere to the tools or machined surface [12]. This is not the case with thermoset materials that are not reformable at high temperatures. To investigate machining thick thermoplastic composites for blade roots, drilling was attempted on a 56-mm thick thermoplastic laminate (64-ply Saertex triax fiberglass infused with Elium resin), using the same machining methods that are typically used for a thermoset composite blade. Shown in Figure 6, an 11/16-in. hole was drilled into the laminate with no observed melting or deterioration of the thermoplastic resin.

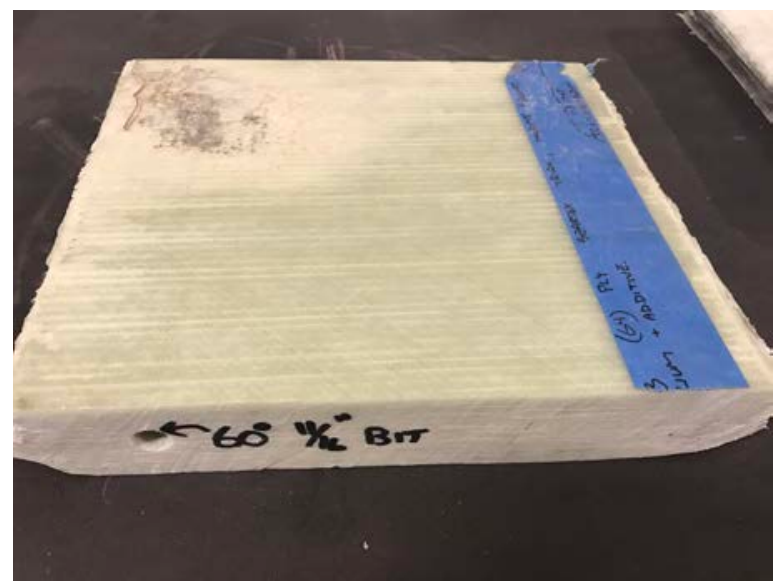

Figure 6. Hole drilled in 56-mm-thick laminate.

\section{BLADE MANUFACTURING}

\section{Shear web}

The shear web is the internal structure of the blade that forms an I-beam when connected to the two spar caps that extend the span of the LP and HP of the blade skins. The shear web was the first whole 9-m blade component manufactured with the Elium thermoplastic resin. TABLE 3 shows the laminate schedule and materials used for this part.

\begin{tabular}{l|ll}
\multicolumn{3}{l}{ TABLE 3. LAYUP AND MATERIAL DETAILS FOR THE SHEAR WEB. } \\
\hline Layer & \multicolumn{1}{c}{ Material } & \multicolumn{1}{c}{ Details } \\
\hline 1 & Veil & Single layer \\
2,3 & Biax fiberglass & Two layers, $0.75 \mathrm{~mm}$ thick per layer \\
4 & Armacell foam & $3 / 8$ in. thick \\
5,6 & Biax fiberglass & Two layers, $0.75 \mathrm{~mm}$ thick per layer \\
\hline
\end{tabular}

The resin mixture for the shear web consisted of Elium mixed with 3\% Luperox and no ECA. The infusion process and final part are shown in Figure 7. 


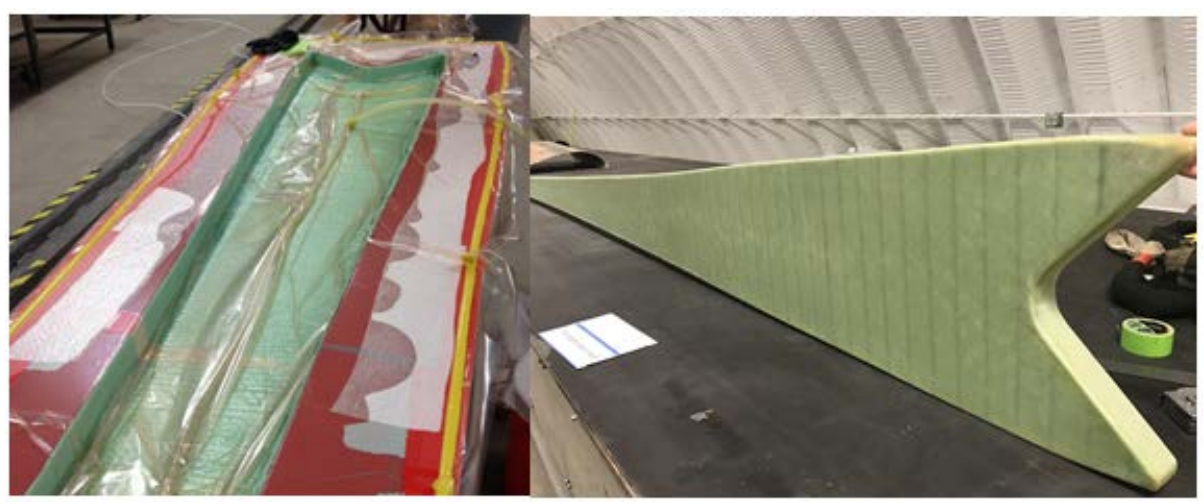

Figure 7. Shear web layup and resin infusion photographs: the infusion process (left), and the finished product (right).

The resin was mixed and infusion was started from a feed line at the root first, followed by a feed line approximately two-thirds down the span 10 minutes later. The root of the shear web was fully wet out in approximately 10 minutes; however, the Compoflex flow media ended 3 feet from the tip, resulting in approximately 100 minutes of infusion time for the entire shear web. A second shear web was manufactured after the blade was complete, and the flow media was extended to the tip. This part was fully wet out within 30 minutes, suggesting that the longer time for the first shear web was because of the lack of flow media at the tip.

During the peak exothermic reaction, the resin reached $100^{\circ} \mathrm{C}$ in some areas, and small localized areas of boiling were observed on the surface of the Compoflex under the vacuum bag. However, no defects were noticed after the resin dropped back to room temperature, and therefore did not affect the part. It is thought that this outcome was a result of the four layers of fiberglass and 3/8-in.-thick core material resulting in a resin-rich area that had a high exothermic temperature that was not controlled like it was for the thick root trial because of the lack of the ECA. The shear web was demolded after being left for approximately 2 hours after cure.

\section{Blade skins}

The LP skin was manufactured first, followed by the HP skin. TABLE 4 shows the layup and materials used for both skins. This section focuses on manufacturing the LP skin, however, a similar methodology was used for the HP skin. Separate batches of the resin were mixed for the root section and the outer span of the blade. The root resin was mixed with $2 \%$ Luperox and 800 ppm of ECA to decrease the peak exotherm in the thicker section, wherein more resin would accumulate. The resin for the remaining blade span was mixed with 3\% Luperox and no ECA. Similar to the thick root trial, a 4-in.-wide layer of chop strand mat $\left(225 \mathrm{~g} / \mathrm{m}^{2}\right)$ was placed under the spar cap and wrapped around to the top of the final layup to allow resin to get into underside of the thick root. 
TABLE 4. LAYUP AND MATERIAL DETAILS FOR THE LOW-PRESSURE SKIN.

\begin{tabular}{|c|c|c|}
\hline Layer & Material & Details \\
\hline 1 & Gel coat & Marine Clear, MEKP \\
\hline 2 & Veil & Single layer \\
\hline 3 & Triax fiberglass & Single layer, $0.88 \mathrm{~mm}$ thick \\
\hline 4 & $\begin{array}{l}\text { Spar cap (pultruded } \\
\text { unidirectional carbon) }\end{array}$ & Starting $150 \mathrm{~mm}$ from root \\
\hline 5 & $\begin{array}{l}\text { Spar cap (pultruded } \\
\text { unidirectional carbon) }\end{array}$ & Starting $230 \mathrm{~mm}$ from root \\
\hline 6-39 & Triax fiberglass & $\begin{array}{l}34 \text { tapered layers at the blade root, } 0.88 \mathrm{~mm} \text { thick } \\
\text { per layer }\end{array}$ \\
\hline 40 & Balsa wood, Armacell foam & $\begin{array}{l}\text { Quarter-inch-thick Balsa from root to } 4,182 \mathrm{~mm} \text {, } \\
\text { Quarter-inch thick foam from } 4,182 \mathrm{~mm} \text { to tip }\end{array}$ \\
\hline 41 & Biax & Single layer, $0.74 \mathrm{~mm}$ thick \\
\hline
\end{tabular}

Infusion was started at the thick root section 20 minutes prior to opening the feed lines for the remaining blade span to give more time for the thicker section to infuse. The entire skin took approximately 80 minutes to fully wet out. The resin started to kick at the root section approximately 10 minutes after full wet out. Once the resin began to kick, it heated up quickly, hitting a peak temperature around $90^{\circ} \mathrm{C}$ and decreasing back to room temperature in less than 30 minutes. When the resin returned to room temperature, it was fully cured and hardened, and the part was demolded after being left overnight. The same procedure was used for the HP skin; however, the HP skin was demolded 2 hours after curing with no issues. Figure 8 shows the LP skin manufacturing stages.
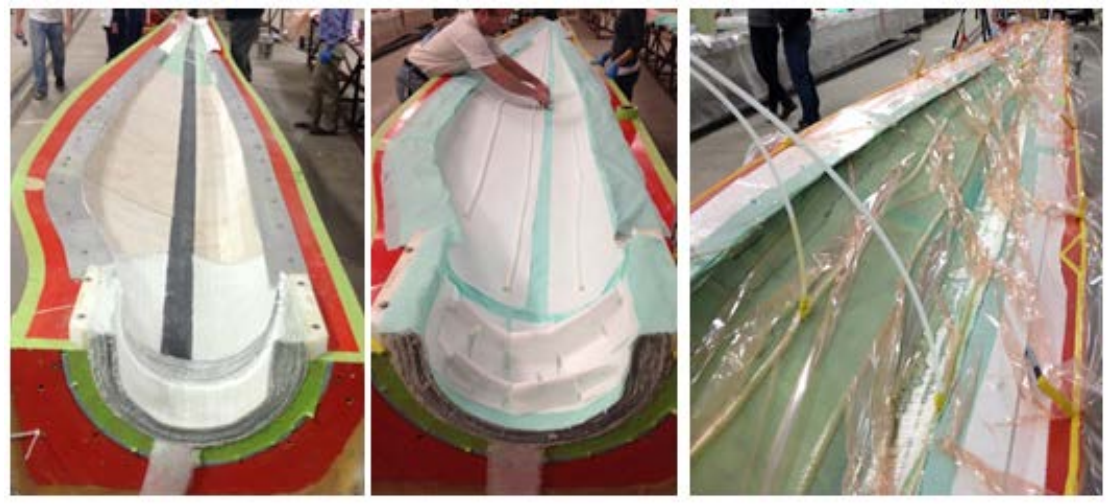

Figure 8. Low-pressure skin process photographs: layup with spar cap and core (left), feed line layout (center), and skin infusion (right).

Several areas under the flanges were rich with resin as a result of race tracking in this area. In addition, the blade tip was the last area to wet out and a small dry spot had to be repaired because of the lack of resin flow. For the HP skin, an extension of the flow media to the tip was used to help promote resin movement in this area, and the fabric was pressed under the flanges more diligently.

The three blade components (LP, HP, and the shear web) were assembled in the low-pressure mold. Prior to assembly, the edges of the blade skins and shear webs were trimmed and sanded to form flush bonding surfaces, and the surfaces were prepared using 50 grit paper and acetone. A SikaAxson epoxy adhesive was tested prior to bonding, and was found to have sufficient open time. Therefore, it was used to bond the three blade components, a process that took approximately 60 minutes. The 
final blade weighed $257 \mathrm{lbs}(116.57 \mathrm{~kg})$ and had a center of gravity at 2,197 $\mathrm{mm}$ from the root. Figure 8 shows the final 9 -m blade after bonding.

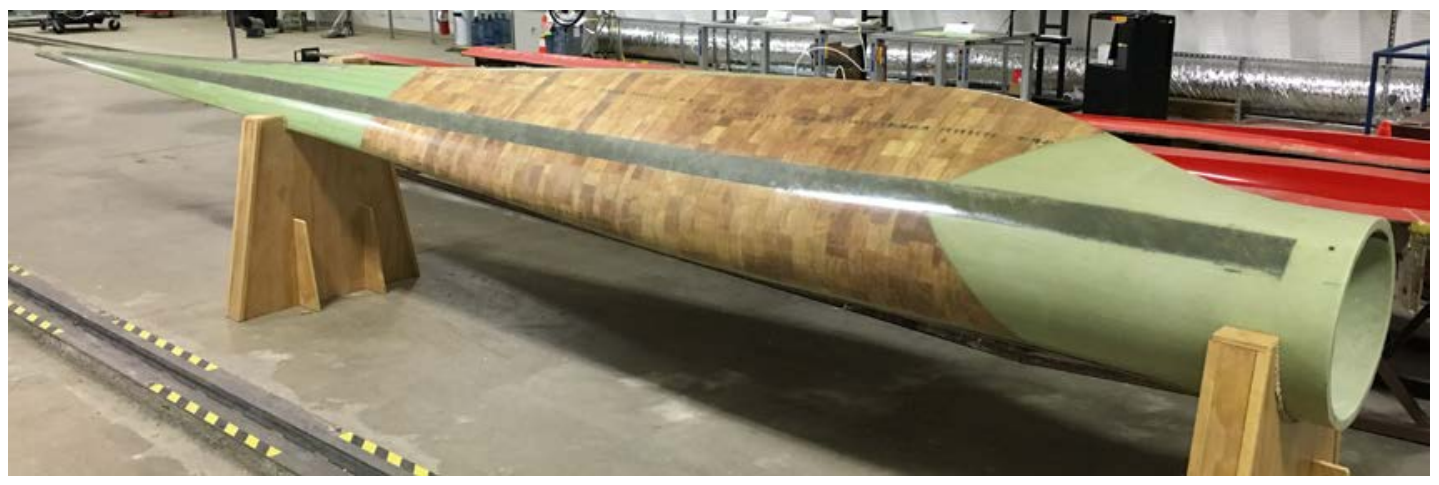

Figure 9. Nine-meter thermoplastic composite blade.

\section{SUMMARY AND DISCUSSION}

The thickness, number of layers, and resin composition of the components manufactured through this work affected the time required for the resin to infuse and cure. Because a greater percentage of the Luperox curing agent resulted in faster cure times, the resin formulations were tailored depending on the section thickness to allow sufficient open time for thicker sections to fully wet out. As well, the amount of ECA used in each part depended on the thickness and the amount of resin accumulation in the laminate stack. TABLE 5 gives a summary of the composition of the resin used for each part manufactured.

\begin{tabular}{|c|c|c|}
\hline Component & Percent Luperox & $E C A$ \\
\hline LP skin & $2 \%$ root, $3 \%$ outer span & Root only \\
\hline HP skin & $2 \%$ root, $3 \%$ outer span & Root only \\
\hline Shear web & $3 \%$ & No \\
\hline Root subsection & $2 \%$ & Yes \\
\hline Max chord subsection \#1 & $2 \%$ & No \\
\hline Max chord subsection \#2 & $2 \%$ & No \\
\hline
\end{tabular}

For the trial root section, the ECA decreased the peak exotherm in the thicker section reasonably, but had too much of a negative effect in the thinner section in the outer span, which cured but did not harden adequately. For the shear web, the thickness of the core material and lack of ECA led to small localized boiling spots, but did not affect the final part. For the blade skin manufacturing, an appropriate resin composition was developed based on the lessons learned from the trial parts, and the ECA was found to maintain the peak exothermic temperatures to a reasonable level such that the exothermic reaction did not compromise the part or damage the tooling.

One of the objectives of this work was to demonstrate the cycle times of a thermoplastic blade. Figure 10 shows the breakdown of the approximate $( \pm 10$ minutes) infusion and cure times for the blade components. 


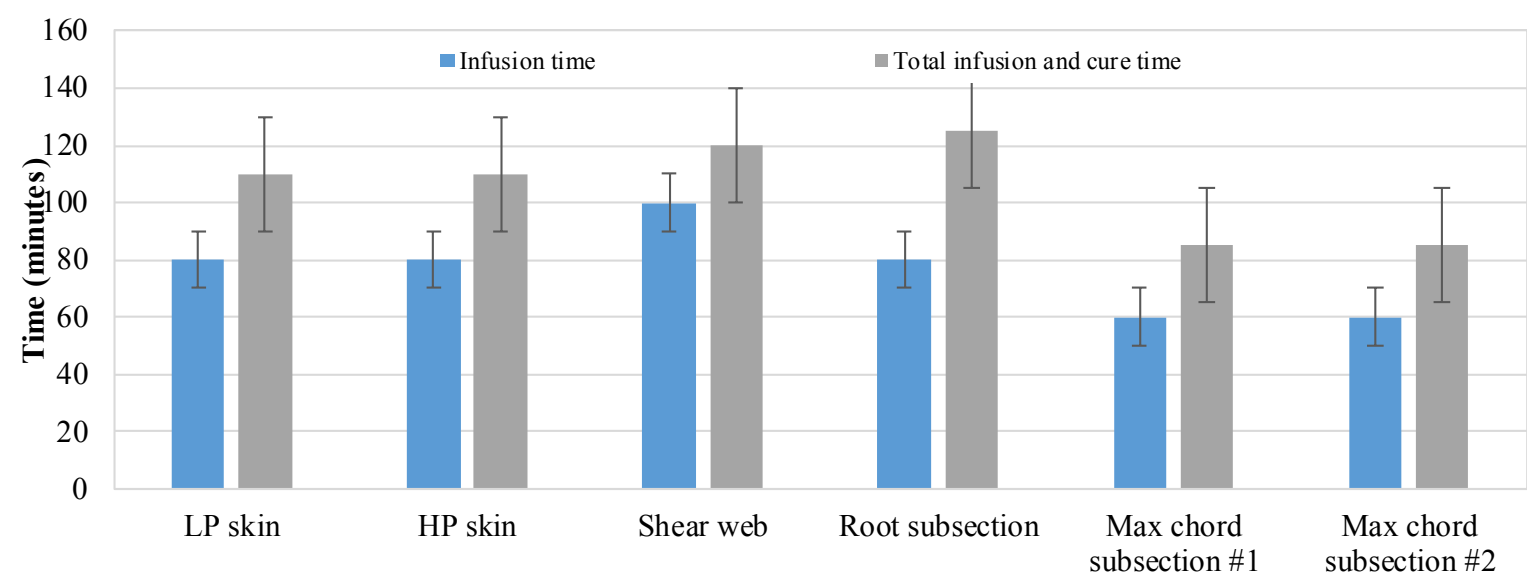

Figure 10. Infusion and demolding times for various components.

In general, the infusion and cure for the 9-m blade skins took less than 3 hours. In several cases, the components were infused in the evening and left in the mold overnight prior to demolding, leading to the higher demolding times shown in Figure 10. The HP skin and shear web were demolded within 2 hours of cure and were unaffected by the shorter demolding times. This outcome is in agreement with the fact that once the thermoplastic resin undergoes the exothermic reaction, it does not require any further processing. Further, it means that the total cycle time from initiating infusion to demolding for a 9-m blade skin can be as low as 3 hours. However, preparing the mold and laying up the materials made up a large percentage of the total cycle time of the blade because of the manual methods used. This information highlights the importance of automation in decreasing manufacturing times. Additionally, delays were encountered when identifying the correct adhesive to use, which resulted in a longer time required to bond the blades. Further studies by participating companies will help alleviate this problem in the future.

\section{CONCLUSIONS}

This work successfully demonstrated the first thermoplastic blade manufactured in the United States to date using VARTM, and proved that fast cure times and energyefficient manufacturing methods are the key advantages of thermoplastic materials. The components manufactured through this work cured at room temperature without requiring applied heat, and infusion and demolding times as low as 3 hours were demonstrated. These results lead to significant time and energy reductions compared to the cure time and energy requirements of thermoset resin materials that are currently being used.

The manufacturing trial discussed in this paper focused on a scale-model blade for pragmatic manufacturing reasons. The next stages of this work are to build full-scale thermoplastic composite blade components at the Composites Manufacturing Education and Technology facility. This process will involve developing manufacturing methods at full scale and structurally validating components to verify their properties. Future work will also investigate methods for thermal welding of blade skins and components, which will eliminate the need for adhesive bonds between blade skins and lead to stronger, longer-lasting blades. Initial trials will be 
performed on laminate test coupons and the structural integrity of the thermally welded bonds will be investigated.

With similar blade manufacturing and reliability challenges being faced in the marine and hydrokinetic industry, the application of thermoplastic composites will also be explored for water energy applications. Epoxy-based composite materials have been shown to have degraded fatigue life and changes in failure modes because of aging in seawater. Future work will investigate water ingress and diffusion kinetics on material coupons made from thermoplastic composites as compared to thermoset materials through accelerated seawater aging.

\section{ACKNOWLEDGMENTS}

A team of 11 industrial partners, including Arkema Inc., Johns Manville, TPI Composites Inc., Huntsman Polyurethanes, Strongwell, DowAksa USA, Chomarat North America, Composites One, SikaAxson, Creative Foam, and Chemtrend provided materials and on-site fabrication support for blade component manufacturing and assembly. Pultruded spar caps were fabricated at Strongwell in Bristol, Virginia, and shipped to the National Wind Technology Center for incorporation into the blade shells. The project was led by the Institute for Advanced Composites Manufacturing Innovation's Wind Technology Area, based at the National Wind Technology Center at NREL, with support from Oak Ridge National Laboratory, the U.S. Department of Energy's Advanced Manufacturing Office, and the Advanced Industries Program administered by the Colorado Office of Economic Trade and Development.

This work was supported by the U.S. Department of Energy under Contract No. DE-AC36-08GO28308 with the National Renewable Energy Laboratory. Funding was provided by the DOE Office of Energy Efficiency and Renewable Energy, Wind Energy Technologies Office. The U.S. Government retains and the publisher, by accepting the article for publication, acknowledges that the U.S. Government retains a nonexclusive, paid up, irrevocable, worldwide license to publish or reproduce the published form of this work, or allow others to do so, for U.S. government purposes.

\section{REFERENCES}

1. 20\% Wind Energy by 2030 - Increasing Wind Energys Contribution to U.S. Electricity Supply. 2008, U.S. Department of Energy, Energy Efficiency and Renewable Energy

2. P.J. Schubel, "Technical cost modelling for a generic 45-m wind turbine blade produced by vacuum infusion (VI)." Renewable Energy. 35 (2010)1: 183-189.

3. "Advanced Blade Manufacturing." [web page] February 2017; Available from: https://energy.gov/eere/wind/advanced-blade-manufacturing.

4. C.-H. Ong and S.W. Tsai, Design, manufacture and testing of a bend-twist Dspar, S.N. Laboratories, Editors. 1999, Stanford University.

5. G. Marsh, Could thermoplastics be the answer for utility-scale wind turbine blades? 2010.

6. K. Ramirez-Tejeda, D.A. Turcotte, and S. Pike, "Unsustainable Wind Turbine Blade Disposal Practices in the United States." New Solutions. 26 (2017)4: 581-598. 
7. R. Cherrington, et al., "Producer responsibility: Defining the incentive for recycling composite wind turbine blades in Europe." Energy Policy. 47 (2012): 13-21.

8. D. Berry, "IACMI/Wind Technology Area." Presented at Sandia Blade Workshop. 2016.

9. D.S. Berry, Blade System Design Studies Phase II: Final Project Report. 2008, TPI Composites, Inc. and Sandia National Laboratories.

10. S. Young and D. Penumadu, In-Plane Shear Stress-Strain Behavior of Elium, Epoxy, and Nylon (Updated with Elium UD and Additional 0/90 Samples). 2016, University of Tennessee.

11. S.O. Ismail, H.N. Dhakal, I. Popov, and J. Beaugrand, "Comprehensive study on machinability of sustainable and conventional fibre reinforced polymer composites." Engineering Science and Technology, an International Journal. 19 (2016)4: 2043-2052.

12. T. Upmeier and D. Biermann, "Deep Hole Drilling of Thermoplastics." 